RU Неологизмы в сфере образования в период пандемии коронавируса (на примере немецкого языка)

\author{
Нагуманова В. А.
}

\begin{abstract}
Аннотация. Цель исследования - выявить особенности словообразования новой лексики, отражающей трансформации в образовательном процессе в условиях пандемии в Германии и вошедшей в словарь неологизмов Института немецкого языка. Научная новизна заключается в классификации новых лексических единиц, появившихся в немецком языке в условиях пандемии, по понятийным областям и описании специфики их образования. Полученные результаты показали, что большая часть новообразований представлена существительными, образованными путем словосложения, при этом треть из них - английского происхождения или состоит из элементов, имеющих английское происхождение.
\end{abstract}

\title{
Neologisms in the Field of Education during the Coronavirus Pandemic (by the Example of the German Language)
}

\author{
Nagumanova V. A.
}

\begin{abstract}
The purpose of the study is to identify word formation features of the new vocabulary that reflects the transformations in the educational process during the pandemic in Germany and has been included in the dictionary of neologisms of the Institute for the German Language. Scientific novelty lies in classifying new lexical units that have appeared in the German language during the pandemic according to conceptual areas and their formation specifics. The attained results showed that most of the coinages are represented by nouns formed by compounding, with a third of them being of English origin or consisting of elements of English origin.
\end{abstract}

\section{Введение}

Пандемия коронавируса, став глубоким социальным потрясением, породила значительное количество неологизмов в современном немецком языке, что отмечают ученые из Института немецкого языка (IDS) в Мангейме. Данный институт является авторитетным центром изучения и документирования современного немецкого языка. В период пандемии (с марта 2020 г.) лингвисты ведут словарь неологизмов (Nеuеr Wortschatz rund um die Coronapandemie [13]) и выявляют особенности их употребления [11; $12 ; 15 ; 16]$.

О скорости прироста лексики можно судить по следующим данным. По состоянию на 9 июля 2020 года данный список содержал 471 единицу [6, с. 111], в октябре 2020 г. - примерно 850 единиц [5, с. 890], на момент начала написания статьи, 26 июня 2021, - 1461 слово.

Данная статья посвящена проблеме обогащения словарного состава немецкого языка в период пандемии коронавируса в сфере образования. Актуальность данного исследования обусловлена необходимостью изучения новой лексики, которая отражает экстралингвистические процессы развития общества во время пандемии. Язык пандемии становится своего рода буфером между человеком и окружающей действительностью [3, с. 159], помогает адаптироваться к быстро меняющимся условиям, способствует переосмыслению понятий. Пандемийную действительность создают человек и реальность, а язык выступает как средство отражения результата их взаимодействия. Соответственно, изучение неологизмов, ставших своего рода «маркерами современности», будет способствовать более глубокому пониманию протекающих в обществе процессов.

Целью данного исследования является изучение неологизмов, появившихся в сфере образования и вошедших в словарь неологизмов Института немецкого языка. Поставленная цель предполагает решение следующих задач: распределить по тематическим областям словарь неологизмов (экономика, политика, медицина, образование, организация досуга, протесты и т.д.), провести количественный и качественный анализ 
новообразований. Методом сплошной выборки были отобраны неологизмы, связанные непосредственно с трансформациями, произошедшими в сфере образования во время пандемии коронавируса. Отобранные лексические единицы были проанализированы с точки зрения структуры, распределены по типу словообразования.

Материалом исследования послужили неологизмы, зафиксированные в словаре неологизмов Института немецкого языка с начала пандемии коронавируса. Сегодня исследователи определяют неологизм как многоплановое явление, требующее междисциплинарного подхода к изучению [4, с. 104]. В настоящей статье единицей исследования является неологизм, под которым понимается новое слово или выражение, а также новое значение уже известного слова или выражения, появившийся в немецком языке с начала пандемии и зафиксированный в списке неологизмов Института немецкого языка. При этом, как отмечается на сайте данного Института, ученые еще наблюдают за распространением и употреблением внесенных в список новообразований.

Теоретической базой исследования послужили работы российских и немецких исследователей, анализирующих процессы возникновения, образования и распространения неологизмов во время пандемии коронавируса, таких как С. В. Буренкова [1], Н. С. Годжаева [2], С. В. Лебедева, Е. И. Ерпилова [4], Ю. М. Шемчук [7], С. Иннервинклер (S. Innerwinkler) [10], А. Клоза-Кюкельхаус (A. Klosa-Kückelhaus) [11], К. Mepc (Ch. Möhrs) [12], K. Ремер (Ch. Römer) [14], Г. Цифонун (G. Zifonun) [16].

Практическая значимость работы заключается в том, что материалы исследования могут быть использованы в вузах гуманитарного направления на спецкурсах или спецсеминарах по неологизмам в немецком языке.

\section{Основная часть}

Из 1461 слова в списке неологизмов 475 лексических единиц относятся к сфере медицины, а именно связаны с вирусом и его распространением, тестами, протеканием болезни, лечением, состоянием пациентов, прививкой и соответствующими документами. Остальные неологизмы описывают трансформации в сфере общества, касающиеся работы, обучения, новых правил нахождения в обществе, мероприятий и организации досуга в условиях пандемии, политики, работы предприятий, сферы услуг, демонстраций, протестов и даже процесса совершения покупок. Примечательно, что на медицинскую сферу приходится чуть больше трети новых слов (примерно 33\%), тогда как на трансформации в жизни общества - больше половины (67\%).

71 слово относится непосредственно к сфере образования, что составляет примерно 5\% от общего числа слов, появившихся во время пандемии в Германии. Следует отметить, что в данный список не вошли лексические единицы, которые могут относиться и к другим сферам жизни общества. Например, неологизмы, которые образуют словообразовательное гнездо с вершиной Zoom, такие как Zoomfatigue (усталость или выгорание, вызванное чрезмерным использованием платформы Zoom), zoomen (использовать платформу Zoom для общения или работы) или Zoomhintergrund (виртуальный фон в Zoom) и др. Единственный неологизм с компонентом Zoom, который относится исключительно к сфере образования - Zoomschule (проведение занятий в учебном заведении с помощью платформы Zoom). Несомненно, в учебных заведениях, как и в любых других общественных местах, актуальна лексика с компонентом Abstand (расстояние, дистанция), например, Аbstandhalten (соблюдение дистанции между людьми в общественных местах во время пандемии), Abstandsnudel (специальная палка для занятий в бассейне, которая помогает соблюдать дистанцию во время пандемии).

Несмотря на то, что доля слов, появившихся в образовательном дискурсе не так велика по сравнению с долей слов, связанных с медициной и другими сферами жизни общества, качественный анализ лексики показывает, насколько глубоко затронула пандемия образовательные процессы.

Неологизмы, появившиеся для описания процессов, происходящих в сфере образования, являются преимущественно существительными, что свидетельствует о необходимости дать определение новым реалиям в учебном процессе.

Наибольшее количество лексических единиц (27) связано с описанием нового формата занятий, особенностями организации и проведения занятий. Дистанционный формат занятий отражается с помощью элементов Digital (digitales Klassenzimmer - занятие, которое проводится с помощью видеоконференции на различных онлайн-платформах), Fern (digitaler Fernunterricht, Fernbeschulung - проведение занятия педагогом с помощью современных технологий без прямого контакта с учащимися), Online (Onlinestunde - онлайнурок), Distanz (Distanzunterricht, Distanzlernen - проведение занятия педагогом с помощью современных технологий без прямого контакта с учащимися), Geister (Geistervorlesung - лекция в высшем учебном заведении, которая проводится с помощью видеоконференции), Virtuell (virtuelles Klassenzimmer - занятие, которое проводится с помощью различных онлайн-платформ).

Проведение занятий на свежем воздухе как одна из вынужденных мер в условиях пандемии также повлекло за собой появление новой лексики с синонимичными компонентами Draußen (Draußenschule - занятие, которое проводится под открытым небом, за пределами здания школы, Draußentag - день, когда занятия проводятся за пределами школы) и Outdoor (Outdoorklasse - группа школьников, занятия у которых периодически проходят под открытым небом, за пределами здания школы).

Система организации занятий, когда их часть проводится в школе, а остальные - онлайн, получила выражение в сложных существительных и словосочетаниях, в том числе заимствованных из английского языка (Wechselunterricht, Wechselmodell, Halbklassenunterricht, Hybridunterricht, rollierendes System, Blended Learning - смешанное обучение). 
В целом, реалии учебного процесса в условиях пандемии, а именно столкновение двух миров - реального и виртуального, офлайн и онлайн, отражаются в антонимической паре Präsenzlehre - Digitallehre.

Экзамены в условиях пандемии стали своеобразным вызовом как для выпускников школ и студентов, так и для учителей и преподавателей ВУЗов. На их долю приходится в словаре неологизмов 18 лексических единиц с элементами Klausur (fernüberwachte Klausur - письменный экзамен, который проводят с использованием современных технологий, при этом с помощью видеокамеры наблюдают за тем, чтобы испытуемый самостоятельно выполнял задания), Exam (Take-home-Exam - экзамен, который сдают из дома, без прямого контакта с экзаменатором), Prüfung (Präsenzprüfung - формат экзамена, при котором экзаменатор и студент находятся в одном помещении), Abitur (Durchschnittsabitur -документ с оценкой за выпускной экзамен, выставленной на основании результатов обучения за последние два года, дающий право поступления в ВУЗ). Для описания процедуры наблюдения за дистанционным экзаменом в Германии стали использовать заимствованное из английского языка слово Proctoring (вместо немецкого варианта Prüfungsbeaufsichtigung).

В словарь неологизмов также вошли 13 лексических единиц, описывающие особенности прохождения учебы в университете во время пандемии. Большая часть из них образованы с помощью словосложения, путем добавления различных элементов к слову Semester, например, Ausnahmesemester (семестр-исключение, обучение в котором велось преимущественно онлайн в связи с ограничениями, введенными в условиях пандемии), Kreativsemester (семестр, в рамках которого был применен творческий подход в образовательном процессе с целью приспособления к новым условиям), Nullsemester, Nichtsemester (нулевой семестр, семестр, который не будет засчитан, т.е. студентам придется потратить больше времени на прохождение своей учебной программы, чем предполагалось до пандемии), создания словосочетания с прилагательными virtuell (virtuelles Auslandssemester - семестр за рубежом, в рамках которого принимающий университет в связи с пандемией предлагает онлайн-курсы), hybrid (hybrides Semester - семестр, в рамках которого занятия проводятся онлайн и офлайн), digital (digitales Semester - семестр, в рамках которого процесс обучения проходит онлайн).

Оставшиеся слова в данной сфере пока не представляется возможным поделить на группы. Данные лексические единицы связаны с запасом масок в школе (Anschubreserve), распространением вируса (Safe-SchoolStudie), технической стороной учебного процесса (PDF-Schleuder, Servicelearning), взаимодействием с родителями (Elternchat) и др. Примечательно, что появился неологизм digitale Didaktik, отражающий, вероятно, новый и весьма перспективный раздел в педагогике, изучающий проблемы обучения в цифровой реальности.

На момент написания статьи ни одно слово не вошло в онлайн-версию словаря Duden в том значении, в котором оно появилось во время пандемии.

Корнеобразующий элемент Corona используется в 9 словах, что составляет 13\% от общего числа (Coronajahrgang - поколение выпускников, которые в связи с пандемией находятся в менее выгодных условиях для старта профессиональной карьеры, Coronanotabitur - свидетельство с выпускными оценками, выставленными на основе обучения за последние два года или выпускные экзамены в гимназиях, которые проходят в особых условиях в связи с пандемией, и т.д.), ни одно слово не содержит компонент Covid. Для сравнения: из 1461 слова в словаре неологизмов 331 слово содержит элемент Corona и 95 - Covid, что составляет $29 \%$.

21 слово - английского происхождения или включает в себя элемент, имеющий английское происхождение, что составляет 30\% от общего количества слов в этой сфере. Большинство лексических единиц представляют собой существительные-композиты, образованные путем объединения эндогенных (исконно немецких) и экзогенных (заимствованных) элементов, например, с элементом Online (Onlineunterricht - онлайнзанятие), Team (Teamlehrkraft - специально обученные кадры, берущие на себя проведение офлайн-занятий вместо учителей, которые в условиях пандемии не могут лично присутствовать на занятии). При этом полностью заимствованных лексических единиц всего три - Blended Learning, Blended Mobility, Proctoring.

Примечательно, что в большинстве случаев в сложных существительных с заимствованными элементами именно последний компонент немецкого происхождения, что в плане грамматики, а именно с точки зрения словоизменения, облегчает «адаптацию» слова в языке, т.к. именно по последнему корню в немецком языке определяют род существительного, от него образуют форму родительного падежа, множественного числа. При этом полностью заимствованные слова имеют колебания в роде, числе и падеже, например, форма родительного падежа “des Blended Learning” (смешанное обучение) не имеет окончания -s, хотя у некоторых заимствований оно присутствует, а у слова Blended Mobility (академическая мобильность) не однозначен род, т.к. его употребляют без артикля (“der Begriff (понятие) Blended Mobility”, “das Konzept (концепт) Blended Mobility”) или, указав термин в заголовке, заменяют в тексте на синонимичные выражения (“komplett online” «полностью онлайн», “eine virtuelle Mobilität” - «виртуальная мобильность») [8; 9].

Помимо указанных выше проблем при заимствовании слова целиком могут возникнуть проблемы с толкованием слова, правописанием или, в случае глаголов, с образованием форм прошедшего времени и спряжением.

\section{Заключение}

Проведенный выше анализ позволяет сделать следующие выводы.

Во-первых, в условиях пандемии доля новообразований, появившихся для описания происходящих в образовательном процессе трансформаций, невелика по сравнению с другими сферами. 
Во-вторых, неологизмы выражены преимущественно существительными или словосочетаниями с существительным, а основным способом неологизации стало словосложение.

B-третьих, наибольшее количество новообразований связаны с форматом занятий в условиях пандемии, проведением экзаменов и описанием семестра в университете.

B-четвертых, корнеобразующие элементы Corona и Covid не столь продуктивны в сфере образования по сравнению с другими сферами.

В-пятых, весомая доля неологизмов (30\%) имеет английское происхождение, при этом большая часть из них образована путем объединения немецких и заимствованных элементов.

B-шестых, несмотря на высокие темпы расширения словаря неологизмов, еще достаточно рано судить о темпах распространения новых лексических единиц и их укоренении в языке.

Перспективы дальнейшего исследования предполагают отслеживание появления новых лексических единиц, особенностей распространения и употребления уже зафиксированных неологизмов в академическом дискурсе. Кроме того, исследование целого корпуса неологизмов, распределение неологизмов по понятийным областям, выявление трендов употребления неологизмов в различных типах дискурсов дополнит уже существующие труды по неологии.

\section{Источники | References}

1. Буренкова С. В. Неологизмы немецкого языка: тематика, лингвистические особенности, перевод // Вестник Омского государственного педагогического университета. Гуманитарные исследования. 2020. № 1 (26). С. 59-63.

2. Годжаева Н. С. Неологизмы современного немецкого языка // Вестник Кемеровского государственного университета. Международные отношения. 2014. Т. 2. № 3 (59). С. 279-281.

3. Кобенко Ю. В. Язык и среда. Опыт систематизации данных междисциплинарных исследований. Томск: Изд-во Томского политехн. ун-та, 2017. 214 с.

4. Лебедева С. В., Ерпилова Е. И. Неологизмы. Сущность проблемы // Теория языка и межкультурная коммуникация. 2018. № 3 (30). С. 99-107.

5. Северская О. И. Ковидиоты на карантикулах: коронавирусный словарь как диагностическое поле актуальных дискурсивных практик // Коммуникативные исследования. 2020. Т. 7. № 4. С. 887-906. DOI: 10.24147/ 2413-6182.2020.7(4).887-906

6. Харитонова Е. Ю. Обогащение словарного состава языка в эпоху COVID-19 (на материале немецкого языка) // Актуальные вопросы современной лингвистики: материалы VIII Региональной научно-практической конференции (с международным участием) «Иностранные языки в межкультурном пространстве: методы исследования и технологии обучения» (г. Москва, МГОУ, 25 сентября 2020 г.). Мытищи: Изд-во Московского обл. гос. ун-та, 2021. С. 110-113.

7. Шемчук Ю. М. Неологизмы в немецкоязычном академическом дискурсе как результат влияния коронавирусной пандемии // Теория языка и межкультурная коммуникация. 2020. № 4 (39). С. 185-194.

8. Blended Mobility: die Neugestaltung unserer europäischen Zusammenarbeit [Электронный ресурс]. URL: https://www.schooleducationgateway.eu/de/pub/latest/news/blended-mobility-europe.htm (дата обращения: 27.07.2021).

9. Erasmus+ Auslandsaufenthalte in Zeiten der Corona-Pandemie [Электронный ресурc] // URL: https://www.nabibb.de/fileadmin/user_upload/na-bibb.de/Dokumente/02_Berufsbildung/01_Mobilitaet/05_Durchfuehrung/2020/ Informationen_Blended_Mobility.pdf (дата обращения: 27.07.2021).

10. Innerwinkler S. Neologismen. Heidelberg: Universitätsverlag Winter, 2015. $72 \mathrm{~S}$.

11. Klosa-Kückelhaus A. Über Corona sprechen: eine besondere Zeit und ihre Folgen [Электронный pecyрc] // Aktuelle Stellungnahmen zur Sprache in der Coronakrise. Mannheim: Leibniz-Institut für Deutsche Sprache (IDS), 2021. URL: https://www.ids-mannheim.de/fileadmin/aktuell/Coronakrise/Klosa_Corona_FOLK.pdf (дата обращения: 27.07.2021).

12. Möhrs Ch..,Schule trotz(t) Corona“: Schule unter dem Sprachlichen Einfluss der Corona-Pandemie [Электронный ресурс] // Aktuelle Stellungnahmen zur Sprache in der Coronakrise. Mannheim: Leibniz-Institut für Deutsche Sprache (IDS), 2020. URL: https://www.ids-mannheim.de/fileadmin/aktuell/Coronakrise/moehrs_ schule.pdf (дата обращения: 27.07.2021).

13. Neuer Wortschatz rund um die Coronapandemie [Электронный ресурс] // OWID. URL: https://www.owid.de/docs/ neo/listen/corona.jsp (дата обращения: 27.07.2021).

14. Römer Ch. Der deutsche Wortschatz. Tübingen: Narr, 2019. 234 S.

15. Wolfer S., Koplenig A., Michaelis F., Müller-Spitzer C. cOWIDplus Analyse: wie sehr schränkt die Corona-Krise das Vokabular deutschsprachiger Online-Presse ein? [Электронный ресурс] // Aktuelle Stellungnahmen zur Sprache in der Coronakrise. Mannheim: Leibniz-Institut für Deutsche Sprache (IDS), 2020. URL: https://www.idsmannheim.de/fileadmin/aktuell/Coronakrise/mueller-spitzer_2.pdf (дата обращения: 27.07.2021).

16. Zifonun G. Anglizismen in der Coronakrise [Электронный ресурс] // Aktuelle Stellungnahmen zur Sprache in der Coronakrise. Mannheim: Leibniz-Institut für Deutsche Sprache (IDS), 2020. URL: https://www.idsmannheim.de/fileadmin/aktuell/Coronakrise/zifonun_anglizismen.pdf (дата обращения: 27.07.2021). 


\section{Информация об авторах | Author information}

RU Нагуманова Вера Александровна ${ }^{1}$, к. филол. н.

${ }^{1}$ Московский государственный институт международных отношений (университет) МИД России

EN Nagumanova Vera Aleksandrovna ${ }^{1}, \mathrm{PhD}$

${ }^{1}$ Moscow State Institute of International Relations (MGIMO University)

${ }^{1}$ v.nagumanova@my.mgimo.ru

\section{Информация о статье | About this article}

Дата поступления рукописи (received): 29.07.2021; опубликовано (published): 30.09.2021.

Ключевые слова (keywords): неологизм; образование; пандемия; немецкий язык; словарь неологизмов; neologism; education; pandemic; German language; dictionary of neologisms. 